Review Article

\title{
Alginate Biosynthesis in Azotobacter vinelandii: Overview of Molecular Mechanisms in Connection with the Oxygen Availability
}

\author{
Ivette Pacheco-Leyva, Felipe Guevara Pezoa, and Alvaro Díaz-Barrera \\ Escuela de Ingeniería Bioquímica, Pontificia Universidad Católica de Valparaíso, Avenida Brasil 2147, Casilla, 4059 Valparaíso, Chile \\ Correspondence should be addressed to Alvaro Díaz-Barrera; alvaro.diaz@ucv.cl
}

Received 28 August 2015; Revised 11 January 2016; Accepted 7 February 2016

Academic Editor: Mukund Adsul

Copyright (C) 2016 Ivette Pacheco-Leyva et al. This is an open access article distributed under the Creative Commons Attribution License, which permits unrestricted use, distribution, and reproduction in any medium, provided the original work is properly cited.

\begin{abstract}
The Gram-negative bacterium Azotobacter vinelandii can synthetize the biopolymer alginate that has material properties appropriate for plenty of applications in industry as well as in medicine. In order to settle the foundation for improving alginate production without compromising its quality, a better understanding of the polymer biosynthesis and the mechanism of regulation during fermentation processes is necessary. This knowledge is crucial for the development of novel production strategies. Here, we highlight the key aspects of alginate biosynthesis that can lead to producing an alginate with specific material properties with particular focus on the role of oxygen availability linked with the molecular mechanisms involved in the alginate production.
\end{abstract}

\section{Introduction}

Increasing research on the mechanisms of synthesis and biochemical properties of biopolymers, such as polysaccharides, led to improving production process and new applications in diverse areas, mainly in food and pharmaceutical industries [1]. One of the main advantages for the use of biopolymers is its degradability, making them a renewable product option. However, the high costs of biopolymer production are still a major drawback for a widespread industrial application [2].

A particular linear polysaccharide with broad growing interest is alginate, which is a structural component of the brown marine algae and the cell wall of bacteria belonging to the Pseudomonas and Azotobacter genera [3-5]. The properties of alginates in solution largely depend on four factors: (a) its monomer chemical composition ( $\beta$-D-mannuronic acid (M-residues) and its epimer, $\alpha$-L-guluronic acid (Gresidues)); (b) the sequence pattern of the monomers; (c) the molecular weight (MW) of the resulting polysaccharide chain; and (d) modifications of the polymer (acetylation degree) $[6,7]$.

However, algal alginates are complex mixtures containing polysaccharides with a wide range of MW and ratios of
M: G. Hence alginates with specific defined $M: G$ ratios or a constant range of MW cannot be easily obtained from particular algae species, due to intrinsic environmental culture conditions, thus limiting their use in the pharmaceutical and chemical industries (more details in Section 2). For this reason, the bioprocesses research area has become interested in developing strategies to produce alginates with particular molecular characteristics through microbial alginate production. In contrast to algal alginates, microbial alginates present exclusive M-residue acetylation, controlled M: G ratios, and specific MW under specific growth conditions [8-10]. A nonpathogenic bacterium able to produce alginate with high production yields in bioreactors is Azotobacter vinelandii. Yet, the complex regulatory pathways controlling the alginate biosynthesis and material properties in response to external environmental clues remain still unknown, despite some efforts in trying to gain new insights into gene expression patterns under different culturing conditions in $A$. vinelandii cultures $[9,11-13]$.

In this review, we present an up-to-date biosynthetic overview of microbial alginate biosynthesis from Azotobacter vinelandii, and the perspectives for production process improvement based on a better understanding on the 


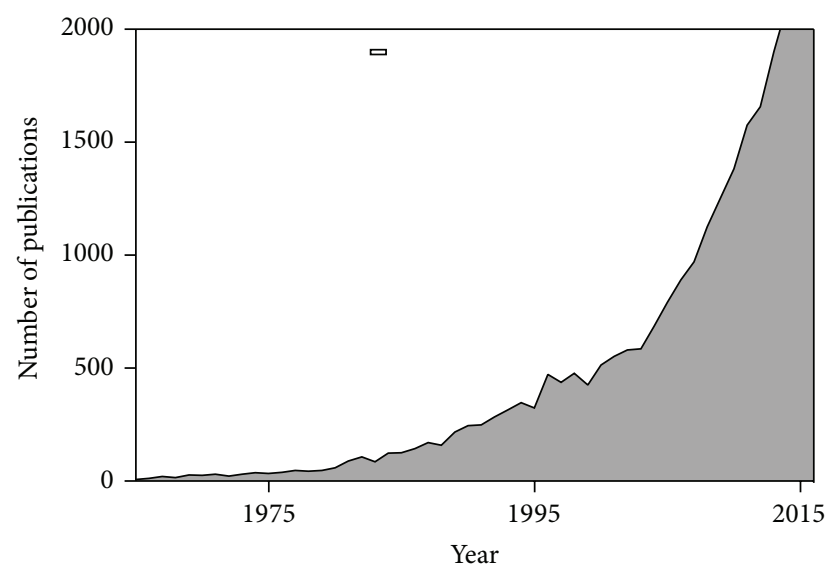

(a)
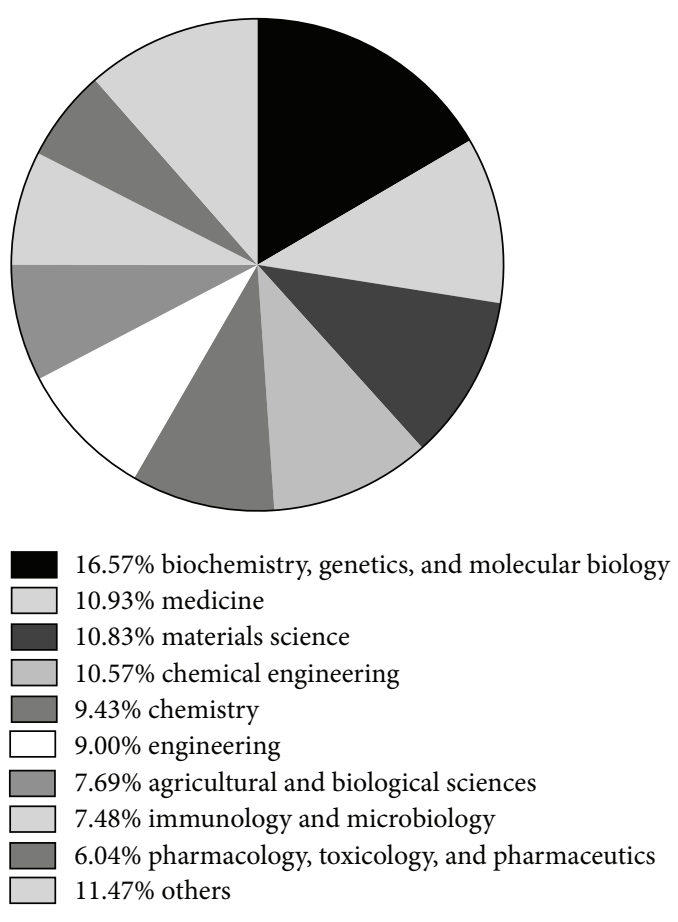

Total $=43600$

Figure 1: (a) Number of publications indexed in Scopus database (August 2015), using keyword alginate (-) in title, abstract, or keywords. (b) Percentage of the word alginate distributed in different subject areas.

molecular mechanism underlying polymer biosynthesis in relationship with the oxygen availability during the fermentation process.

\section{Alginate Structure, Chemical Structure, and Applications}

Over the past 40 years, a growing interest in the use of alginate has been observed including different areas, ranging from genetics to pharmaceutics (Figure 1).

Alginate has been placed as the second biopolymer derived from seaweeds with greater demand in the
TABLE 1: Summary of biotechnological and pharmaceutical applications of alginates based on their molecular weights.

\begin{tabular}{lcr}
\hline Application of alginate & $\begin{array}{c}\text { Molecular } \\
\text { weight } \\
(\mathrm{kDa})\end{array}$ & Reference \\
\hline $\begin{array}{l}\text { Delivery of bioactive compounds } \\
\text { Antioxidant }\end{array}$ & $\approx 15-120$ & {$[60-66]$} \\
$\begin{array}{l}\text { In vivo tissue scaffolds } \\
\text { Antibacterial }\end{array}$ & & \\
$\begin{array}{l}\text { Dietary supplement } \\
\text { Cell immobilization }\end{array}$ & & \\
\hline $\begin{array}{l}\text { Food stabilizer and preserving } \\
\text { agent }\end{array}$ & & \\
$\begin{array}{l}\text { Microencapsulation and storage } \\
\text { stability }\end{array}$ & & \\
Antibacterial \\
Bioremediation \\
Wound healing
\end{tabular}

hydrocolloids' industry [14]. Currently, the only economic way to obtain commercial alginate used for most applications is through its extraction from marine algae, the cost of which ranges between US $\$ 2$ and $20 / \mathrm{kg}$, and with a total market value of around US\$339 million [14]. Furthermore, alginates of very high purity are used in the pharmaceutical industry where they are sold for up to US\$ $3,200 / \mathrm{kg}$.

Since alginate is a biodegradable and a biocompatible polysaccharide, it presents a panoply of food, pharmaceutical, and biotechnological applications (Figure 1(b)). In the food and pharmaceutical industries, alginate is mainly used as a stabilizing, thickening, or gel-film-forming agent $[6$, 15-17], Table 1; in medicine it is used as wound healing material [18], as part of medical treatments $[19,20]$, or as dietary fiber supplements [21, 22]. Alginate showed potential beneficial physiological effects in the gastrointestinal tract [23]. Moreover, hydrogel-alginates are being investigated in biotechnology as drug delivery agents, as cell encapsulation material, and as scaffold material in tissue engineering [24].

Alginate is the main structural component of brown marine algae (Laminaria and Macrocystis) representing about $32 \%$ of dry biomass [25], consisting in variable amounts of M-, G-, and MG-residues, linked by $1 \rightarrow 4$ glycosidic bonds [7]. On the other hand, alginates produced by bacteria are submitted to esterification with $O$-acetyl groups at the $O$ 2 and/or $O-3$ of the M-residues [26], where the majority of the $\mathrm{M}$-residues are mono- $\mathrm{O}$-acetylated, and infrequently with 2,3-di-acetylated [27] (Figure 2). Because the monomeric chemical structure of bacterial alginate and the sequence length determine the mechanical properties of the alginates, one of the aims of different investigations is the possibility of manipulating the composition alginates for specific applications have been intensively investigated $[28,29]$.

The obligate aerobe bacterium Azotobacter vinelandii produces alginate that acts as a diffusion barrier for nutrients and oxygen $[30,31]$. It was reported as a bacterium with a 


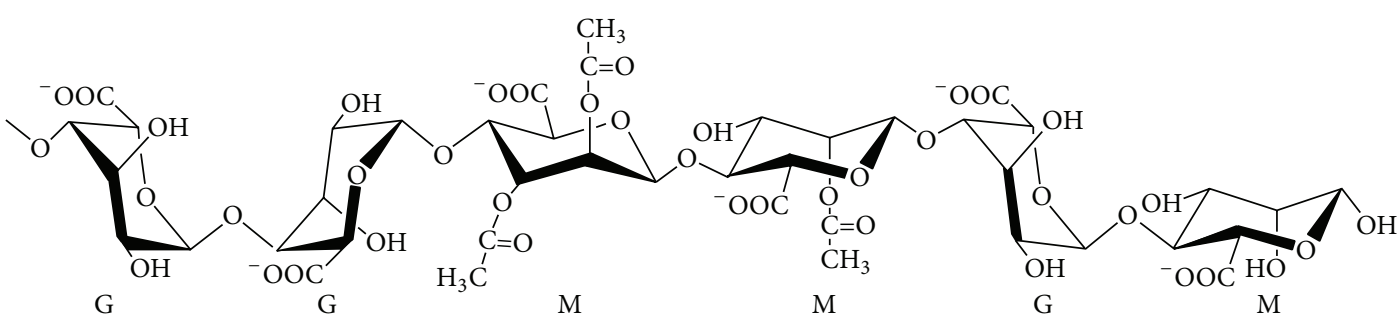

FIGURE 2: Representation of the chemical structure from acetylated alginates produced by Azotobacter vinelandii bacterium [28]. Mannuronic $(\mathrm{M})$ and guluronic $(\mathrm{G})$ acid residues are represented in the alginate chain.

highest respiratory rate [32], implying that it adjusts oxygen consumption rates in order to maintain low levels of cytoplasmic oxygen and in this way permitting the oxygen-sensitive enzymes to be active, like nitrogenase, which is responsible for fixing nitrogen $[30,32]$.

A. vinelandii under limitation of carbon source or by induction forms cysts that are more resistant to desiccation and is mainly composed of alginate $[33,34]$. It also accumulates the intracellular polyester poly- $\beta$-hydroxybutyrate $(\mathrm{PHB})$ as a reserve carbon and energy source $[35,36]$.

Consequently, an increased knowledge about the molecular mechanism involved in alginate biosynthesis will be crucial for the development of novel strategies to improve the production of alginates with defined characteristics tailored for specific applications.

\section{The Biosynthetic-Secretory Route of Alginate Production in Azotobacter vinelandii}

Microbial polysaccharides have distinct biological functions, as intracellular storage, as envelope, or as extracellular polymers [37]. Microbial alginate is an extracellular polysaccharide as xanthan, cellulose, and sphingan, among others, and they differ in their biosynthetic pathways routes (recently reviewed in Schmid et al. 2015 [37]). Moreover, alginate is secreted trough a secretion system shared among the Gramnegative bacteria [38].

The alginate biosynthesis in bacteria Azotobacter results from a complex regulatory network of proteins, similar to Pseudomonas genera $[6,28,39]$.

All of the steps involved in the conversion of central sugar metabolites into the alginate precursor in $A$. vinelandii have been previously identified and characterized $[6,40]$. The alginate precursor, GDP-mannuronic acid, is synthesized from fructose-6-phosphate to mannose-6phosphate by the bifunctional enzyme phosphomannose isomerase (PMI)/guanosine-diphosphomannose pyrophosphorylase (GMP), designated as AlgA, encoded by the algA gene. A phosphomannomutase (AlgC) directly converts the mannose-6-phosphate into mannose-1-phosphate, which is in turn converted into GDP-mannose by the AlgA enzyme. GDP-mannose is oxidized to GDP-mannuronic acid by GDPmannose dehydrogenase ( $\mathrm{Alg} \mathrm{D}$, encoded by $\operatorname{alg} \mathrm{D}$ gene). Because the intracellular levels of GDP-mannose are high and because it is used in different pathways, it has been proposed as the limiting step of alginate biosynthesis in $P$. aeruginosa [41].

After the production of the polymer precursor GDPmannuronic acid precursor, its polymerization and transport across the cytoplasmic membrane is carried out by proteins presumably integrating a cytoplasmic membrane complex (polymerase complex). The core of the polymerase complex is composed of the glycosyltransferase Alg8 protein and Alg44 protein [42-44]. Furthermore, the protein AlgK is thought to stabilize the polymerase complex, by interacting with Alg44 [43]. Highlighting the important role of this protein, alginate polymerization does not occur in the absence of $\operatorname{alg} K[42,45]$.

The polymannuronate polysaccharide resulting from polymerization and then translocation to the $A$. vinelandii periplasm is composed of M-residues, which can then be further modified during its passage across the periplasm [43]. These modifications consist in acetylation, epimerization, and degradation of the M-residues. More specifically, the polymannuronic molecule undergoes an $\mathrm{O}$-acetylase modification, which is catalyzed by an acetylase enzymatic complex composed of AlgI, AlgV (AlgJ in P. aeruginosa), AlgF, and AlgX proteins [46-48]. While M-residue $O$-acetylation does not occur frequently in alginate, some may be acetylated. $\mathrm{O}$-acetylated M-residues will therefore be protected from epimerization [26], because only nonacetylated M-residues can be epimerized to G-residues by the AlgG epimerase [42], so alginates with a relatively high degree of acetylation display a lower degree of epimerization [27].

Alginate depolymerization occurs at the 4-O-glycosidic bond via $\beta$-elimination, by alginate lyases which have been the subject of a recent review [28]. The Azotobacter vinelandii genome encodes six enzymes with alginate lyase activity [31]: the alginate lyase $\operatorname{AlgL}$ [49], the bifunctional mannuronan C-5 epimerase and alginate lyase AlgE7 [50], the three AlyA(1-3) lyases [51], and an exolyase, AlyB, that is still uncharacterized [28].

Some of the nonacetylated M-residues are then epimerized to G-residues by the bifunctional AlgG epimerase, which converts $\operatorname{poly}(\beta$-D-mannuronate) to $\alpha$-L-guluronate. In $P$. aeruginosa, $\mathrm{AlgG}$ is also part of the periplasmic protein complex that serves as a scaffold for leading the newly formed alginate polymer through the periplasmic space to the outer membrane secretin AlgE porin (AlgJ in $A$. vinelandii) [52]. A scaffold complex helps to transport the recently modified polysaccharide throughout the periplasm towards AlgE before secretion to the extracellular milieu. This 
Synthesis and polymerization of precursors

Periplasmic and extracellular modifications

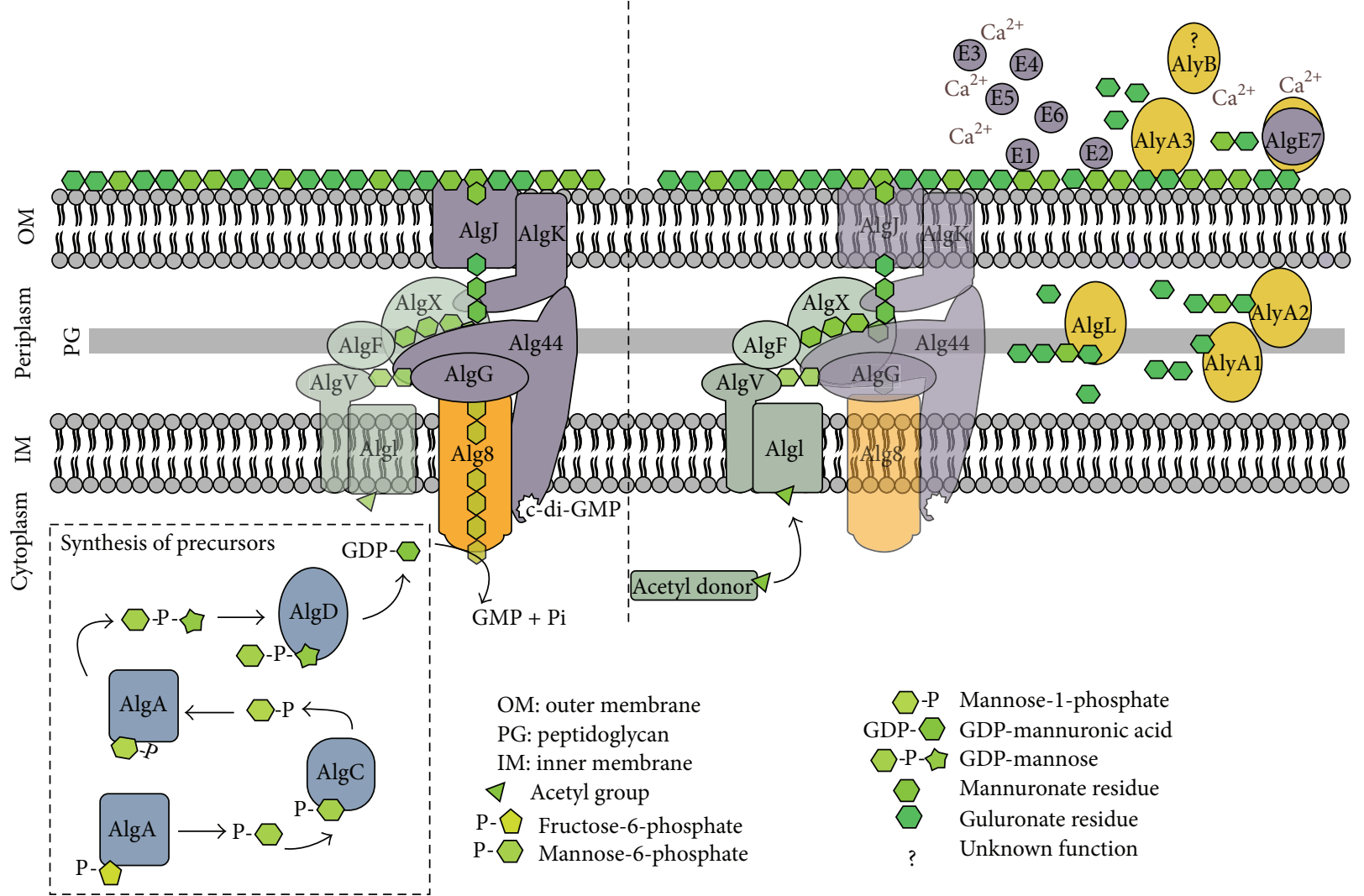

FIgure 3: Schematic representation of the alginate biosynthetic steps in Azotobacter vinelandii, from evidence-based protein-protein interaction in $P$. aeruginosa $[28,42,43]$. The biosynthetic alginate pathway is represented as two complementary stages: on the left, the synthesis of the substrate precursor (GDP-mannuronic acid) and its following polymerization, including transfer from cytoplasm; on the right, the modification (periplasmic and extracellular) of the nascent polymer, as well as the export through the outer membrane of the polymer.

complex is thought to be composed of $\mathrm{AlgG}$, $\mathrm{AlgK}$, and $\mathrm{AlgX}$ proteins and possibly AlgL [40, 42, 43, 52]. The exported polysaccharide could be then epimerized by seven extracellular $\mathrm{Ca}^{2+}$-dependent epimerases (AlgE1-7) [53]. Based on these evidences, Figure 3 shows a schematic representation of the alginate biosynthetic steps in $A$. vinelandii.

\section{Genetic Regulation of Alginate Biosynthesis in Azotobacter vinelandii}

In Azotobacter vinelandii the alginate biosynthetic gene cluster is arranged as an operon (Figure 4), containing genes coding for enzymes involved in the synthesis of the alginate precursors, as well as those involved in its polymerization, degradation, acetylation, epimerization, and secretion. The availability of the complete genome sequence of $A$. vinelandii [31] also contributes to the better knowledge of this organism.

Several promoters controlling alginate gene cluster transcription have been described: algD 1 ( $\sigma^{\mathrm{D}}$ promoter), algD 2 (AlgU $\sigma^{\mathrm{E}}$ dependent promoter), and $\operatorname{alg} D p 3$ promoters, all located upstream of algD $[54,55]$, alg $8 p$ promoter, upstream of alg8 [44], and a promoter for sigma 70 located upstream of $\operatorname{alg} G$ [49]. In addition, two putative promoters $\operatorname{alg} C p 1$ and $\operatorname{algCp2}$ are situated upstream of $\operatorname{alg} C$ gene (Figure 4) [56].

The alginate biosynthetic gene cluster expression is controlled by algUmucABCD gene cluster, where algU encodes the alternative sigma $\sigma^{\mathrm{E}}$ factor (AlgU), essential for alginate production [57]. Moreover, $\mathrm{AlgU}$ is responsible for transcription driven by the $\operatorname{alg} C p 1$ and $\operatorname{algDp} 2$ promoters (Figure 5), but it does not control the algL or the algA genes, as described for $P$. aeruginosa [55].

The MucA and MucC proteins negatively regulate alginate production, acting as anti- $\sigma^{\mathrm{E}}$ factors [54]. MucA represses $\mathrm{Alg} \mathrm{U}$ protein activity, thus suppressing $\operatorname{alg} D$ transcription from the $\operatorname{alg} D p 2$ promoter. In contrast, $\operatorname{alg} U$ gene transcription is autoregulated by $\mathrm{AlgU}$ interaction and activation of its $\sigma^{\mathrm{D}}$ promoter locus (algUp2) (Figure 5) [54].

Additionally, expression of the algD promoters is controlled by the global two-component system GacS/GacA, which is conserved among Gram-negative bacteria [58]. The GacS/GacA system controls alginate biosynthesis [58], where $\mathrm{GacS}$ controls the expression of algD from its three promoters [58]. Accordingly, mutations in gacS and gacA significantly reduce the algD transcript levels [58]. GacA not only is a positive regulator of the biosynthesis of alginate and PHB [58] 


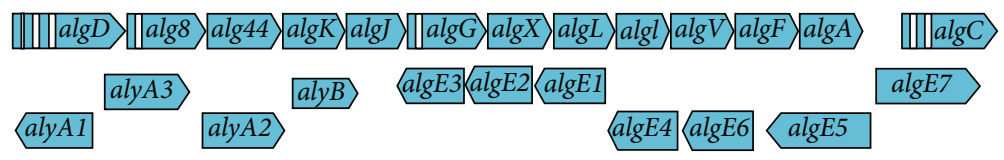

FIGURE 4: Genetic structure genes involved in alginate biosynthesis and modification in Azotobacter vinelandii. Gene operon for alginate biosynthesis algD-A, and algC gene is transcribed separately; aly $A 1-3$ and aly $B$ alginate lyases encoding genes, and algE1-7 the epimerases genes.

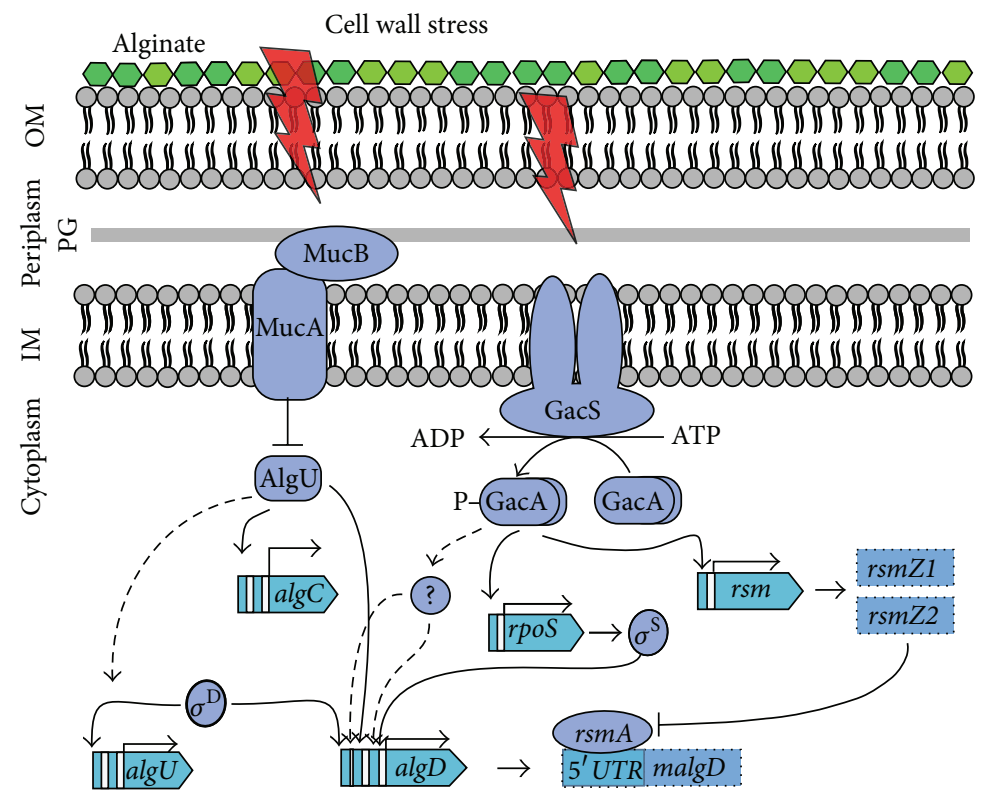

FIGURE 5: Regulation of alginate biosynthetic genes in A. vinelandii (modified according to reference [40]). Promoters are indicated as banners; mRNAs are indicated as dotted boxes; solid lines indicate the reported mechanism of regulation, and dashed lines indicate unknown mechanism of gene regulation; arrows indicate positive regulation and T-shaped bars indicate negative regulation. OM: outer membrane; PG: peptidoglycan; IM: inner membrane. See text for a more detailed description.

but also regulates alginate biosynthesis through activation of the small regulatory RNAs, Rsm (rsmZ1 and rsmZ2). These RNAs interact with the rsmA protein, which binds algD mRNA and thus acts as a transcriptional repressor [59]. The A. vinelandii genome encodes nine small RNAs belonging to the Rsm posttranscriptional regulatory system ( $r s m Z 1-7$ and rsmY1-2) (Figure 5) [59].

Despite the great efforts to understand the alginate biosynthetic gene regulation, little is known about how cultivation conditions could modify gene transcription in $A$. vinelandii.

\section{Alginate Production in Azotobacter vinelandii Cultures: The Balance of Alg8 and AlgL by Oxygen Availability}

The glycosyltransferase Alg8 protein belongs to the glycosyltransferase type II family and is localized in the inner cell membrane [78]. The glycosyltransferase type II enzyme family catalyzes the transfer of glycosyl residues to an acceptor molecule, during biosynthesis of polysaccharides, such as the cellulose or chitin synthase [79].
In both Azotobacter vinelandii and Pseudomonas aeruginosa the alg8 gene encodes the Alg8 protein [44]. In P. aeruginosa it has been demonstrated that by adding additional copies of alg8 it is possible to increase alginate production by at least 10 times [80], suggesting that this protein might be involved in a rate-limiting step of alginate production. As a consequence, the possibility of manipulating Alg8 protein levels in $A$. vinelandii may be a valuable approach for increased alginate production, although this has not being done so far. The attempts to reach high Alg8 protein levels were by manipulating the alg8 gene expression via culture conditions. However, it is important to note that alginate production in A. vinelandii is a multienzymatic and complex process.

Moreover, the Alg44 protein acts as link between Alg8 and the AlgJ alginate exporter protein [42, 43]. Since Alg44 has a c-di-GMP intracellular binding domain, it was suggested that this protein presents a regulatory role [81]; although the c-di-GMP levels might not have an impact neither on Alg44 stability nor on its localization, it still seems to be required for the activation of Alg8 [42, 43].

Interestingly, in A. vinelandii batch, cultures controlling the dissolved oxygen tension (DOT) at $1 \%$ present higher 
TABLE 2: Molecular weight of alginate and relative gene expression of alg 8 and $\operatorname{alg} L$ with respect to the $q_{\mathrm{O}_{2}}$ variations.

\begin{tabular}{lcc}
\hline Specific oxygen uptake rate $\left(\mathrm{mmol} \mathrm{g}^{-1} \mathrm{~h}^{-1}\right)$ & $1-5$ & $5-10$ \\
\hline Alginate molecular weight $(\mathrm{kDa})$ & $500-1350$ & $480-870$ \\
algL gene expression (fold change) & Until 15 & $0.5-1.5$ \\
alg8 gene expression (fold change) & Until 9.0 & $1.0-2.0$ \\
\hline
\end{tabular}

Source: $[9,11-13]$.

levels of alg8 and alg44 gene expression, when compared with control cultures (5\% DOT) [9]; the authors suggested that this behavior can in turn enhance the MW of the alginate produced under low DOT conditions. Moreover, in continuous cultures under non-nitrogen-fixation conditions at different agitation rates $(300,500$, and $700 \mathrm{rpm})$ and different sucrose concentration in the feed medium, the highest alginate MW (obtained at $500 \mathrm{rpm}$ ) is correlated with the highest alg8 expression [12], suggesting that alg8 gene expression can be modulated by not only oxygen availability but also carbon source feed rate, as well. The oxygen availability here is perceived as the amount of oxygen needed for full oxidation of carbon source, taking into account the oxygen transfer rate as well as the DOT level in cultures [82]. Meanwhile, in chemostat cultures under nitrogen-fixation conditions, operated at a dilution rate of $0.07 \mathrm{~h}^{-1}$, expression of both alg 44 and $\operatorname{alg} 8$ was affected by changes in agitation rate $(400,500$, and $800 \mathrm{rpm}$ ), implying that the activity of both genes could be controlled by oxygen availability [13]. Although the highest alginate MW was obtained at $500 \mathrm{rpm}$, this was not correlated with higher alg8 gene expression, which was obtained at $800 \mathrm{rpm}$. The differences between the two-chemostat culture conditions might be explained by the activation of the nitrogenase protection machinery (non-nitrogen-fixation versus fixation), where the higher alginate MW have directly linked to the alg8 gene expression under nonfixing conditions. This notion agrees with the fact that nitrogenase activity protects cells from oxygen, thus fostering alginate production [30,83]. Other possible explanation given is that the culture condition might activate the genes coding for alginate lyases, further discussed in this review. However, more studies are needed, especially those involving gene expression and proteomics profiles during $A$. vinelandii cultures in order to have a better insight of alginate polymerization step.

A possible link among the low specific oxygen uptake rate $\left(q_{\mathrm{O}_{2}}\right)$, the MW of the alginate synthesized, and alg8 gene expression was found [11]. This work suggests that when the $q_{\mathrm{O}_{2}}$ value increases by double, the MW of alginate decreases (about 1.6 times), while alg8 relative expression decreases around sixfold. Moreover, in cultures carried out in continuous mode operated at dilution rate $0.08 \mathrm{~h}^{-1}$, when the $q_{\mathrm{O}_{2}}$ value was $2.2 \mathrm{mmolg}^{-1} \mathrm{~h}^{-1}$, both the alginate $\mathrm{MW}$ and alg8 gene expression levels were higher than those obtained in cultures in which the $q_{\mathrm{O}_{2}}$ value was double [11]. The same correlation between low $q_{\mathrm{O}_{2}}$ value and highest alginate MW was reported [12], where a slight increment of 1 in the $q_{\mathrm{O}_{2}}$ lead to a reduction in the MW of the alginate produced by A. vinelandii (from 1200 to $500 \mathrm{kDa}$ ). Furthermore, in this condition, the lyase-encoding gene algL increased its expression by threefold while alg8 expression decreased by ninefold. Interestingly, for $q_{\mathrm{O}_{2}}$ values below $2 \mathrm{mmolg}^{-1} \mathrm{~h}^{-1}$ [12] or exceeding $5 \mathrm{mmol} \mathrm{g}^{-1} \mathrm{~h}^{-1}[9,13]$, the changes in the alginate MW were not correlated with $\operatorname{alg} 8$ or $\operatorname{alg} L$ gene expression levels. Table 2 summarizes the major changes observed on both the alginate MW and gene expression levels, during the small increment values over the specific oxygen uptake rate of $A$. vinelandii cultures.

Furthermore, the Azotobacter vinelandii genome encodes six enzymes with alginate lyase activity [31]: the alginate lyase $\operatorname{AlgL}$ [49], the bifunctional mannuronan C-5 epimerase and alginate lyase AlgE7 [50], and the three AlyA(1-3) lyases [51].

The AlyA1, AlyA2, and AlyA3 belong to the PL7 polysaccharide lyase family, containing an alginate lyase module, linked to three calcium-binding modules $[28,51]$. AlyA1 and AlyA2 are more likely to be periplasmic (AlyA1, UniProtKBM9YEJ6; AlyA2, UniProtKB-C1DHI8) whereas the AlyA3 protein has secreted signal C-terminal domain (AlyA3, UniProtKB-C1DQS5), which is needed for efficient germination in A. vinelandii [51]. In chemostat cultures, conducted at dilution rate of $0.07 \mathrm{~h}^{-1}$ with agitation of $500 \mathrm{rpm}$, highest alginate MW was reported [13]. In this condition, an increment in the agitation rate (from 400 to $600 \mathrm{rpm}$ ) leads to an increment in the lyase-encoding genes alyA1, algL, and alyA2 by twofold.

The algGXLIVFA operon encodes the AlgL protein responsible for the periplasmic alginate lyase activity in $A$. vinelandii. Disruption of the algL gene generated a strain that overproduces alginate, suggesting that this enzyme is important for alginate biosynthesis [84]. Furthermore, the increase in $\operatorname{alg} L$ expression was not correlated with a decrease in alginate MW in chemostat cultures [12]. However, algL gene expression pattern could also be affected by the $q_{\mathrm{O}_{2}}$ (manipulated by changes in the agitation rate) in chemostat. Supporting this observation, chemostat cultures also showed an increase in $\operatorname{algL}$ gene expression (around eightfold) together with higher MW alginate production [11, 12]. By using an $A$. vinelandii mutant strain carrying algL::WGm nonpolar mutation [84] and culturing under 3\% of DOT, no alterations were found in alginate lyase activity in culture broth comparing with the wild-type strain. However, alginates with a high MW were obtained [85], suggesting that the lower MW of the alginate correlates with the higher alginate lyase AlgL activity.

In A. vinelandii ATCC 9046 strain cultures carried out at 1 and $5 \%$ DOT, the expression of higher alginate lyase genes (algL, alyA1, alyA2, alyA3, and algE7) correlated with the lower DOT and with the higher MW alginate production [9]. In these conditions (1\% DOT), the intracellular and extracellular lyase activities were lower, comparing with cultures grown at 5\% DOT, suggesting that dissolved oxygen affected the activity of the alginate lyases and/or their gene expression. However, the alginate lyase activity (intracellular and extracellular) seemed to be associated with the exponential phase of the cultures, where, in the ATCC strain cultured, the maximum of alginate lyase activity was found in the prestationary phase and dropping in the stationary phase $[9,85]$.

As stated previously (Table 2), in cultures with $q_{\mathrm{O}_{2}}$ between $2 \mathrm{mmol} \mathrm{g}^{-1} \mathrm{~h}^{-1}$ and $5 \mathrm{mmolg}^{-1} \mathrm{~h}^{-1}[9,11-13]$, the 
activity of intracellular lyases, namely, AlgL, presented a basal level which was not correlated with a rise in their gene transcriptional levels [9]. This behavior per se may explain the observed rise in alginate MW (Table 2). Even though these observations indicate that dissolved oxygen affects intracellular as well as extracellular alginate lyase activities, it is possible that different alginate lyases could be expressed at different physiological states, as suggested by the study of AlyE3, which is essential for the efficient cyst germination in A. vinelandii [51].

It is important to note that although the AlgL is localized in the periplasm, it has an N-terminal secretion signal (AlgL, UniProtKB-O5219), suggesting that AlgL secretion can occur in response to diverse environmental stimuli (i.e., oxygen concentration). This notion is supported by the observation that $\operatorname{AlgL}$ extracellular activity is highly dependent on the dissolved oxygen and that the role of alginate lyase is restricted to a postpolymerization step [9, 85]. Similarly, the alginate lyase AlyA3 also presents extracellular activity, whereas AlyA1 and AlyA2 appear to be periplasmic [51]. These data strongly suggest that alginate lyase expression and extracellular activity occur in response to dissolved oxygen concentrations. Therefore, a detailed analysis of dynamic variations in expression levels and in enzymatic activity throughout the culture is warranted to understand more deeply the alginate polymerization process.

In summary, current evidence indicates that when values of $q_{\mathrm{O}_{2}}$ vary between 2 and $5 \mathrm{mmol} \mathrm{g}^{-1} \mathrm{~h}^{-1}$ in cultures of A. vinelandii, a rise in expression of $\operatorname{alg} L$ together with a decrease in expression of alg8 correlates with a decrease in alginate MW (Table 2). As such, this range of $q_{\mathrm{O}_{2}}$ could be a target in the development of strategies to manipulate the characteristics of alginates.

5.1. Oxygen Sensing Mechanisms in Azotobacter vinelandii. Current evidences demonstrate that the oxygen transfer rate, the dissolved oxygen tension levels, and the oxygen uptake rate affect alginate biosynthesis in $A$. vinelandii cultures $[8,9$, $12,13,36,40,86-89]$. Despite the importance of the oxygen and the intrinsic relationship with it, no strong evidence of the molecular mechanism involved in sensing it during $A$. vinelandii culturing is available, as well as its further downstream mechanism still being lacking. In this section we discuss that oxygen availability during $A$. vinelandii culturing is a key factor and we suggest a possible mechanism of action.

In $A$. vinelandii the mechanism involved in sensing oxygen availability remains to be fully investigated. In bacteria, several oxygen sensing mechanisms exist. However they can be clustered in two groups based on how the signal is perceived. One category can interact with external environment while, on the other hand, the second category senses physiological changes resulting from variations in the external environment. Nevertheless, both sensing mechanisms operating together control directly the switch between aerobic and anaerobic metabolism [90]. Among the oxygen sensing mechanism, the FNR, ArcA/B, and ubiquinone-8 (Q8) are well characterized in E. coli [90].

In $A$. vinelandii the absence of an Fnr-like protein, CydR, overexpressing the $\beta$-ketothiolase and acetoacetyl-coA reductase [91], both enzymes catalyze the production of $\beta$ hydroxybutyryl-CoA, which is the PHB precursor [40]. It has been demonstrated that low aeration culture conditions in $A$. vinelandii cultures enhanced the metabolic flux from pyruvate towards acetyl-CoA. This had an influence on the increment on the metabolic flux towards PHB production, concomitantly with the higher alginate production [8], suggesting that the aeration conditions could affect the alginate production, by regulating possible gene targets of CydR. Supporting this observation, batch cultures of $A$. vinelandii OP mutant strain carried out at $600 \mathrm{rpm}$ showed lowest $q_{\mathrm{O}_{2}}$ compared with wild-type strain (ATCC 9046) [92]. The $A$. vinelandii $\mathrm{OP}$ strain contains an insertion element in the alg $U$ gene, which in turn represses alginate synthesis [93] and it has been suggested that $\mathrm{Alg} \mathrm{U}$ is required for $c y d R$ gene expression [94].

CydR controls the expression of $c y d A B$ operon that encodes a cytochrome $b d$ terminal oxidase, and $c y d A B$ gene expression correlates with the NADH:ubiquinone oxidoreductase activity (NDHII) [91]. In A. vinelandii, the $\mathrm{Na}^{+}$-translocating $\mathrm{NADH}$ :ubiquinone oxidoreductases $\left(\mathrm{Na}^{+}-\mathrm{NQR}\right)$ are encoded in the nqr operon, and it had been linked to regulating negatively alginate production [95]. Additionally, A. vinelandii genome contains genes linked to NADH:ubiquinone oxidoreductases (NDH), the NDH-II type, and 13 genes encoding subunits of NDH-I type [95]. The NADH oxidation in $A$. vinelandii is mediated by two $\mathrm{NADH}$ :ubiquinone oxidoreductases [96], and the fast NADH oxidation is linked to a fast quinone reduction. The $u b i C-A$ operon in $A$. vinelandii is responsible for the transcription of the genes necessaries for Q8 biosynthesis [95]. A mutation in the intragenic region $u b i A$ correlates with lower Q8 protein levels, accompanied with an improvement in the alginate production, but all the more, with a higher expression of biosynthetic alginate genes, $\operatorname{alg} D, \operatorname{alg} C$, and $\operatorname{alg} A$. Moreover, the Q8 protein seems to be responsible for at least $8 \%$ of the respiratory capacity in $A$. vinelandii, during low and high aeration cultures [95].

Interestingly, in other bacteria as E. coli, the role of quinones as a redox signal for the pathways involved in sensing oxygen and regulation of expression of genes involved in oxidative and fermentative catabolism is well known, specifically the ArcB/A two-component system [97-99].

Figure 6 summarizes the plausible regulation of alg genes in $A$. vinelandii, via a signaling cascade activated by oxygen availability. On one hand, the $\mathrm{Na}^{+} \mathrm{NQR}$ protein regulates negatively $\operatorname{alg} D$ and $\operatorname{alg} C$ gene targets, while the ArcB/A twocomponent system regulates algD and alg8 gene expression under oxygen availability. When oxygen is limiting, the sensor kinase ArcB autophosphorylates and then transphosphorylates the regulator ArcA, which activates $\operatorname{alg} D, \operatorname{alg} 8$, and alg44 gene expression. The autophosphorylation of ArcB is inhibited at higher oxygen concentrations, by the accumulation of Q8 (oxidized form). In this sense, in $A$. vinelandii, a tight control of alg genes via a signaling cascade activated by oxygen availability may exist (Figure 6).

Although recently Flores et al., 2015 [36], discussed mainly the influence of the oxygen on production of alginate during $A$. vinelandii cultures, not much attention is paid 


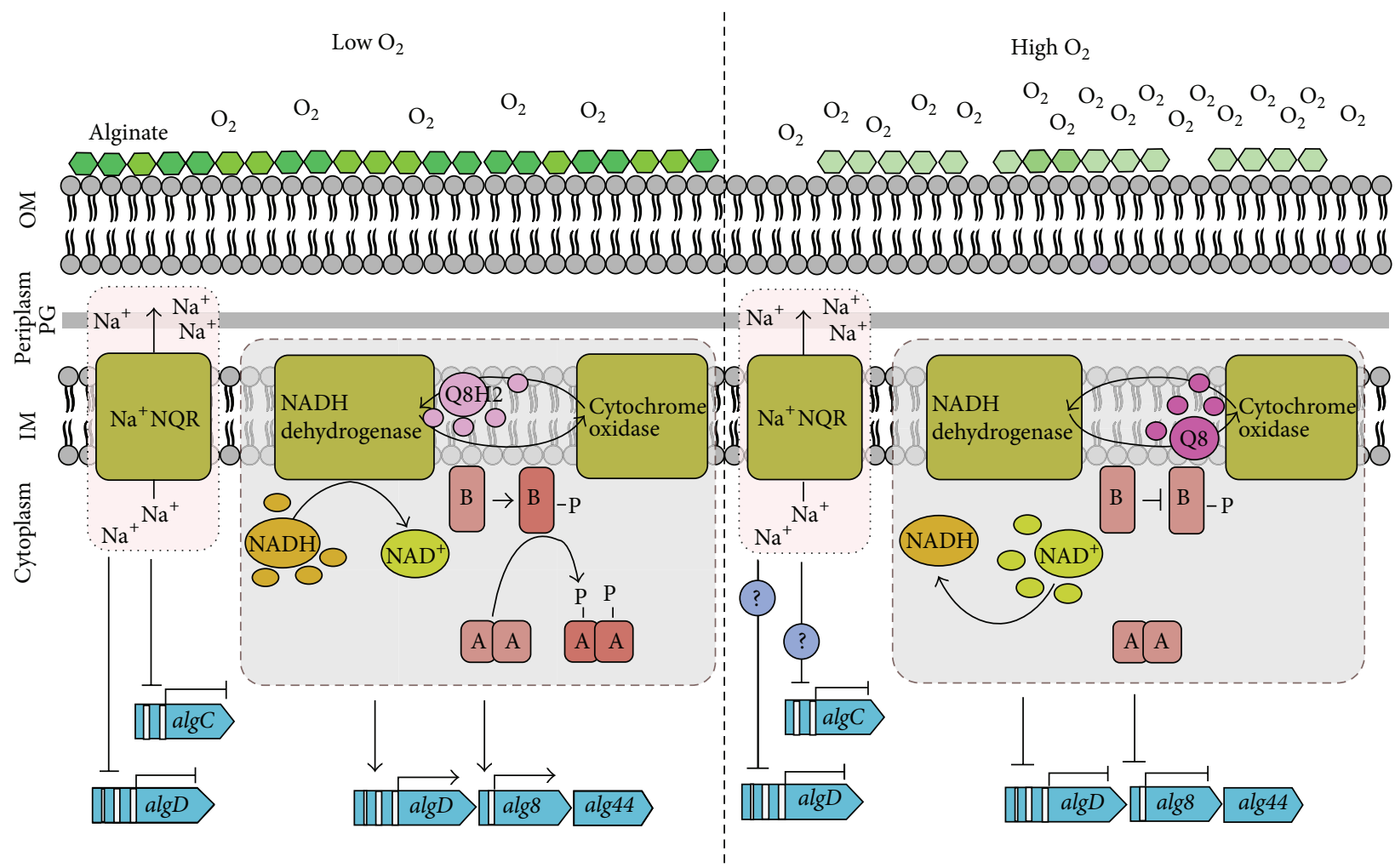

FIGURE 6: Schematic representation of the possible gene regulation mechanism by oxygen in Azotobacter vinelandii. Oxygen availability is depicted in the figure as low $\mathrm{O}_{2}$ (left side) and high $\mathrm{O}_{2}$ (right side). Light red dotted boxes indicate the $\mathrm{Na}^{+}$-translocating NADH:ubiquinone oxidoreductase $\left(\mathrm{Na}^{+} \mathrm{NQR}\right)$ that regulates negatively $\operatorname{alg} D$ and algC gene targets, although the exact mechanism of algD and $\operatorname{algC}$ gene regulation at high $\mathrm{O}_{2}$ by $\mathrm{Na}^{+} \mathrm{NQR}$ is still unknown. Gray slashed boxes represent the ArcB/A two-component redox sensor: under high oxygen availability, the autophosphorylation of $\mathrm{ArcB}$ (B blocks) is inhibited by oxidized quinones (Q8). ArcA (A blocks) in the nonphosphorylated state is unable to bind specifically to $\operatorname{alg} D$, alg8, and alg44 gene targets. Low oxygen causes a decrease in the level of oxidized quinones (Q8H2), allowing the autophosphorylation of ArcA. ArcA-P binds specifically to its target sites and coordinates the cellular response to oxygen availability. Arrows indicate positive regulation and T-shaped bars indicate negative regulation. Flag-type boxes indicate genes described in the figure. Question mark indicates unknown gene regulation mechanism. OM: outer membrane; PG: peptidoglycan; IM: inner membrane.

to which molecular pathways are involved during alginate biosynthesis. In our work, we propose a possible mechanism of action of the oxygen availability during $A$. vinelandii culturing, offering a new path to look at and in this way contributing to the better knowledge of controlling bacterial alginates production.

Despite the enormous efforts in understanding the microbial alginate biosynthesis under defined culture conditions, there is still a way to go. The decoding of the A. vinelandii genome has open the possibility to getting access to new information; however no wide genetic screen studies during alginate production have been reported yet. So, it will be necessarily an improvement in the knowledge of $A$. vinelandii alginate biosynthesis gene regulation in alginate production processes, in order to generate a tailored and affordable alginate product.

\section{Conclusion}

In the present review we discuss that oxygen availability during Azotobacter vinelandii cultures might exert a tight control over the expression of alginate-related genes, which will impact the quality of the polysaccharide or will regulate enzymatic activities that modified the nascent alginate chain. Current evidence indicates a prevailing equilibrium in alg 8 and $\operatorname{alg} L$ gene expression, which is being regulated by oxygen availability. This equilibrium will further impact the alginate molecular weight. Accordingly, more information regarding oxygen sensing, transportation, and signaling pathways during specific culture conditions of $A$. vinelandii will be needed in order to obtain alginates with specific characteristics.

\section{Conflict of Interests}

The authors declare that there is no conflict of interests regarding the publication of this paper.

\section{Acknowledgments}

This work was supported by a Grant from CONICYT-Chile (Project PCCI40039) and DI-PUCV 037-98. The authors 
acknowledge Dr. Nuno Rodrigues Dos Santos for his critical comments on the paper.

\section{References}

[1] B. H. A. Rehm, "Bacterial polymers: biosynthesis, modifications and applications," Nature Reviews Microbiology, vol. 8, no. 8, pp. 578-592, 2010.

[2] S. Bengtsson, A. R. Pisco, M. A. M. Reis, and P. C. Lemos, "Production of polyhydroxyalkanoates from fermented sugar cane molasses by a mixed culture enriched in glycogen accumulating organisms," Journal of Biotechnology, vol. 145, no. 3, pp. 253-263, 2010.

[3] F. Clementi, "Alginate production by Azotobacter vinelandii," Critical Reviews in Biotechnology, vol. 17, no. 4, pp. 327-361, 1997.

[4] D. E. Pszczola, "Discovering treasures of the deep," Food Technology, vol. 52, no. 4, pp. 74-80, 1998.

[5] I. W. Sutherland, Biotechnology of Microbial Exopolysaccharydes, Cambridge University Press, Cambridge, UK, 1990.

[6] U. Remminghorst and B. H. A. Rehm, "Bacterial alginates: from biosynthesis to applications," Biotechnology Letters, vol. 28, no. 21, pp. 1701-1712, 2006.

[7] J. L. Geddie and I. W. Sutherland, "The effect of acetylation on cation binding by algal and bacterial alginates," Biotechnology and Applied Biochemistry, vol. 20, no. 1, pp. 117-129, 1994.

[8] T. Castillo, E. Heinzle, S. Peifer, K. Schneider, and C. F. Peña $\mathrm{M}$, "Oxygen supply strongly influences metabolic fluxes, the production of poly(3-hydroxybutyrate) and alginate, and the degree of acetylation of alginate in Azotobacter vinelandii," Process Biochemistry, vol. 48, no. 7, pp. 995-1003, 2013.

[9] C. Flores, S. Moreno, G. Espín, C. Peña, and E. Galindo, "Expression of alginases and alginate polymerase genes in response to oxygen, and their relationship with the alginate molecular weight in Azotobacter vinelandii," Enzyme and Microbial Technology, vol. 53, no. 2, pp. 85-91, 2013.

[10] Ç. Kıvılcımdan Moral, Ö. Doğan, and F. D. Sanin, "Effect of oxygen tension and medium components on monomer distribution of alginate," Applied Biochemistry and Biotechnology, vol. 176, no. 3, pp. 875-891, 2015.

[11] A. Díaz-Barrera, A. Aguirre, J. Berrios, and F. Acevedo, "Continuous cultures for alginate production by Azotobacter vinelandii growing at different oxygen uptake rates," Process Biochemistry, vol. 46, no. 9, pp. 1879-1883, 2011.

[12] A. Díaz-Barrera, E. Soto, and C. Altamirano, "Alginate production and alg 8 gene expression by Azotobacter vinelandii in continuous cultures," Journal of Industrial Microbiology and Biotechnology, vol. 39, no. 4, pp. 613-621, 2012.

[13] A. Díaz-Barrera, F. Martínez, F. Guevara Pezoa, F. Acevedo, and B. Lin, "Evaluation of gene expression and alginate production in response to oxygen transfer in continuous culture of Azotobacter vinelandii," PLoS ONE, vol. 9, no. 8, Article ID e105993, 2014.

[14] N. Rhein-Knudsen, M. T. Ale, and A. S. Meyer, "Seaweed hydrocolloid production: an update on enzyme assisted extraction and modification technologies," Marine Drugs, vol. 13, no. 6, pp. 3340-3359, 2015.

[15] W. Sabra, A.-P. Zeng, and W.-D. Deckwer, "Bacterial alginate: physiology, product quality and process aspects," Applied Microbiology and Biotechnology, vol. 56, no. 3-4, pp. 315-325, 2001.

[16] B. H. A. Rehm and S. Valla, "Bacterial alginates: biosynthesis and applications," Applied Microbiology and Biotechnology, vol. 48, no. 3, pp. 281-288, 1997.
[17] P. Gacesa, "Bacterial alginate biosynthesis-recent progress and future prospects," Microbiology, vol. 144, no. 5, pp. 1133-1143, 1998.

[18] D. Hoefer, J. K. Schnepf, T. R. Hammer, M. Fischer, and C. Marquardt, "Biotechnologically produced microbial alginate dressings show enhanced gel forming capacity compared to commercial alginate dressings of marine origin," Journal of Materials Science: Materials in Medicine, vol. 26, no. 4, article 162, 2015.

[19] E. Ruvinov and S. Cohen, "Alginate biomaterial for the treatment of myocardial infarction: progress, translational strategies, and clinical outlook," Advanced Drug Delivery Reviews, vol. 96, pp. 54-76, 2016.

[20] J. Venkatesan, I. Bhatnagar, P. Manivasagan, K.-H. Kang, and S.-K. Kim, "Alginate composites for bone tissue engineering: a review," International Journal of Biological Macromolecules, vol. 72, pp. 269-281, 2015.

[21] I. A. Brownlee, A. Allen, J. P. Pearson et al., "Alginate as a source of dietary fiber," Critical Reviews in Food Science and Nutrition, vol. 45, no. 6, pp. 497-510, 2005.

[22] M. G. Jensen, M. Kristensen, and A. Astrup, "Effect of alginate supplementation on weight loss in obese subjects completing a 12-wk energy-restricted diet: a randomized controlled trial," The American Journal of Clinical Nutrition, vol. 96, no. 1, pp. 5-13, 2012.

[23] P. W. Dettmar, V. Strugala, and J. Craig Richardson, “The key role alginates play in health," Food Hydrocolloids, vol. 25, no. 2, pp. 263-266, 2011.

[24] M. Liu, L. Dai, H. Shi, S. Xiong, and C. Zhou, "In vitro evaluation of alginate/halloysite nanotube composite scaffolds for tissue engineering," Materials Science and Engineering: C, vol. 49, pp. 700-712, 2015.

[25] N. V. Konda, S. Singh, B. A. Simmons, and D. KleinMarcuschamer, "An investigation on the economic feasibility of macroalgae as a potential feedstock for biorefineries," BioEnergy Research, vol. 8, no. 3, pp. 1046-1056, 2015.

[26] I. W. Davidson, I. W. Sutherland, and C. J. Lawson, "Localization of $O$-acetyl groups of bacterial alginate," Journal of General Microbiology, vol. 98, no. 2, pp. 603-606, 1977.

[27] G. Skjåk-Bræk, S. Paoletti, and T. Gianferrara, "Selective acetylation of mannuronic acid residues in calcium alginate gels," Carbohydrate Research, vol. 185, no. 1, pp. 119-129, 1989.

[28] H. Ertesvåg, "Alginate-modifying enzymes: biological roles and biotechnological uses," Frontiers in Microbiology, vol. 6, no. 523, 2015.

[29] H. Ertesvåg, S. Valla, and G. Skjåk-Bræk, "Enzymatic alginate modification," in Alginates: Biology and Applications, B. H. A. Rehm, Ed., Microbiology Monographs, pp. 95-115, Springer, Berlin, Germany, 2009.

[30] W. Sabra, A.-P. Zeng, H. Lunsdorf, and W.-D. Deckwer, "Effect of oxygen on formation and structure of Azotobacter vinelandii alginate and its role in protecting nitrogenase," Applied and Environmental Microbiology, vol. 66, no. 9, pp. 4037-4044, 2000.

[31] J. C. Setubal, P. dos Santos, B. S. Goldman et al., "Genome sequence of Azotobacter vinelandii, an obligate aerobe specialized to support diverse anaerobic metabolic processes," Journal of Bacteriology, vol. 191, no. 14, pp. 4534-4545, 2009.

[32] E. Post, D. Kleiner, and J. Oelze, "Whole cell respiration and nitrogenase activities in Azotobacter vinelandii growing in oxygen controlled continuous culture," Archives of Microbiology, vol. 134, no. 1, pp. 68-72, 1983. 
[33] H. L. Sadoff, "Encystment and germination in Azotobacter vinelandii," Bacteriological Reviews, vol. 39, no. 4, pp. 516-539, 1975.

[34] D. Segura, C. Núñez, and G. Espín, "Azotobacter cysts," in Encyclopedia of Life Sciences, John Wiley \& Sons, New York, NY, USA, 2001.

[35] A. Díaz-Barrera and E. Soto, "Biotechnological uses of Azotobacter vinelandii: current state, limits and prospects," African Journal of Biotechnology, vol. 9, no. 33, pp. 5240-5250, 2010.

[36] C. Flores, A. Díaz-Barrera, F. Martínez, E. Galindo, and C. Peña, "Role of oxygen in the polymerization and de-polymerization of alginate produced by Azotobacter vinelandii," Journal of Chemical Technology and Biotechnology, vol. 90, no. 3, pp. 356365, 2015.

[37] J. Schmid, V. Sieber, and B. Rehm, "Bacterial exopolysaccharides: biosynthesis pathways and engineering strategies," Frontiers in Microbiology, vol. 6, 2015.

[38] J. C. Whitney and P. L. Howell, "Synthase-dependent exopolysaccharide secretion in Gram-negative bacteria," Trends in Microbiology, vol. 21, no. 2, pp. 63-72, 2013.

[39] I. D. Hay, Z. U. Rehman, A. Ghafoor, and B. H. A. Rehm, "Bacterial biosynthesis of alginates," Journal of Chemical Technology and Biotechnology, vol. 85, no. 6, pp. 752-759, 2010.

[40] E. Galindo, C. Peña, C. Núñez, D. Segura, and G. Espín, "Molecular and bioengineering strategies to improve alginate and polydydroxyalkanoate production by Azotobacter vinelandii," Microbial Cell Factories, vol. 6, article 7, 2007.

[41] P. J. Tatnell, N. J. Russell, and P. Gacesa, "GDP-mannose dehydrogenase is the key regulatory enzyme in alginate biosynthesis in Pseudomonas aeruginosa: evidence from metabolite studies," Microbiology, vol. 140, no. 7, pp. 1745-1754, 1994.

[42] Z. U. Rehman, Y. Wang, M. F. Moradali, I. D. Hay, and B. H. A. Rehm, "Insights into the assembly of the alginate biosynthesis machinery in Pseudomonas aeruginosa," Applied and Environmental Microbiology, vol. 79, no. 10, pp. 3264-3272, 2013.

[43] M. Fata Moradali, I. Donati, I. M. Sims, S. Ghods, and B. H. Rehm, "Alginate polymerization and modification are linked in Pseudomonas aeruginosa," mBio, vol. 6, no. 3, Article ID e0045315, 2015.

[44] H. Mejía-Ruíz, J. Guzmán, S. Moreno, G. Soberón-Chávez, and G. Espín, “The Azotobacter vinelandii alg8 and alg44 genes are essential for alginate synthesis and can be transcribed from an algD-independent promoter," Gene, vol. 199, no. 1-2, pp. 271-277, 1997.

[45] H. Mejía-Ruíz, S. Moreno, J. Guzmán et al., "Isolation and characterization of an Azotobacter vinelandii algK mutant," FEMS Microbiology Letters, vol. 156, no. 1, pp. 101-106, 1997.

[46] L. M. Riley, J. T. Weadge, P. Baker et al., "Structural and functional characterization of Pseudomonas aeruginosa AlgX: role of Algx in alginate acetylation," Journal of Biological Chemistry, vol. 288, no. 31, pp. 22299-22314, 2013.

[47] M. J. Franklin and D. E. Ohman, "Mutant analysis and cellular localization of the AlgI, AlgJ, and AlgF proteins required for $O$ acetylation of alginate in Pseudomonas aeruginosa," Journal of Bacteriology, vol. 184, no. 11, pp. 3000-3007, 2002.

[48] P. Baker, T. Ricer, P. J. Moynihan et al., "P. aeruginosa SGNH hydrolase-like proteins AlgJ and AlgX have similar topology but separate and distinct roles in alginate acetylation," PLOS Pathogens, vol. 10, no. 8, Article ID e1004334, 2014.

[49] A. Vazquez, S. Moreno, J. Guzmán, A. Alvarado, and G. Espín, "Transcriptional organization of the Azotobacter vinelandii algGXLVIFA genes: characterization of algF mutants," Gene, vol. 232, no. 2, pp. 217-222, 1999.
[50] B. I. G. Svanem, W. I. Strand, H. Ertesvåg et al., "The catalytic activities of the bifunctional Azotobacter vinelandii mannuronan C-5-epimerase and alginate lyase AlgE7 probably originate from the same active site in the enzyme," Journal of Biological Chemistry, vol. 276, no. 34, pp. 31542-31550, 2001.

[51] M. Gimmestad, H. Ertesvåg, T. M. B. Heggeset, O. Aarstad, B. I. G. Svanem, and S. Valla, "Characterization of three new Azotobacter vinelandii alginate lyases, one of which is involved in cyst germination," Journal of Bacteriology, vol. 191, no. 15, pp. 4845-4853, 2009.

[52] S. Jain and D. E. Ohman, "Role of an alginate lyase for alginate transport in mucoid Pseudomonas aeruginosa," Infection and Immunity, vol. 73, no. 10, pp. 6429-6436, 2005.

[53] H. Ertesvåg, H. K. Høidal, I. K. Hals, A. Rian, B. Doseth, and S. Valla, "A family of modular type mannuronan C-5-epimerase genes controls alginate structure in Azotobacter vinelandii," Molecular Microbiology, vol. 16, no. 4, pp. 719-731, 1995.

[54] C. Núñez, R. León, J. Guzmán, G. Espín, and G. SoberónChávez, "Role of Azotobacter vinelandii mucA and mucC gene products in alginate production," Journal of Bacteriology, vol. 182, no. 23, pp. 6550-6556, 2000.

[55] L. Lloret, R. Barreto, R. Léon et al., "Genetic analysis of the transcriptional arrangement of Azotobacter vinelandii alginate biosynthetic genes: identification of two independent promoters," Molecular Microbiology, vol. 21, no. 3, pp. 449-457, 1996.

[56] G. Gaona, C. Núñez, J. B. Goldberg et al., "Characterization of the Azotobacter vinelandii algC gene involved in alginate and lipopolysaccharide production," FEMS Microbiology Letters, vol. 238, no. 1, pp. 199-206, 2004.

[57] S. Moreno, R. Nájera, J. Guzmán, G. Soberón-Chávez, and G. Espín, "Role of alternative $\sigma$ factor AlgU in encystment of Azotobacter vinelandii," Journal of Bacteriology, vol. 180, no. 10, pp. 2766-2769, 1998.

[58] M. Castañeda, J. Sánchez, S. Moreno, C. Núñez, and G. Espín, "The global regulators GacA and $\sigma^{S}$ form part of a cascade that controls alginate production in Azotobacter vinelandii," Journal of Bacteriology, vol. 183, no. 23, pp. 6787-6793, 2001.

[59] J. Manzo, M. Cocotl-Yañez, T. Tzontecomani et al., "Posttranscriptional regulation of the alginate biosynthetic gene algD by the Gac/Rsm system in Azotobacter vinelandii," Journal of Molecular Microbiology and Biotechnology, vol. 21, no. 3-4, pp. 147-159, 2012.

[60] M. A. Azevedo, A. I. Bourbon, A. A. Vicente, and M. A. Cerqueira, "Alginate/chitosan nanoparticles for encapsulation and controlled release of vitamin $\mathrm{B}_{2}$," International Journal of Biological Macromolecules, vol. 71, pp. 141-146, 2014.

[61] X. Zhao, B. Li, C. Xue, and L. Sun, "Effect of molecular weight on the antioxidant property of low molecular weight alginate from Laminaria japonica," Journal of Applied Phycology, vol. 24, no. 2, pp. 295-300, 2012.

[62] C. A. Bonino, M. D. Krebs, C. D. Saquing et al., "Electrospinning alginate-based nanofibers: from blends to crosslinked low molecular weight alginate-only systems," Carbohydrate Polymers, vol. 85, no. 1, pp. 111-119, 2011.

[63] K. Fujiki, H. Matsuyama, and T. Yano, "Protective effect of sodium alginates against bacterial infection in common carp, Cyprinus carpio L.", Journal of Fish Diseases, vol. 17, no. 4, pp. 349-355, 1994.

[64] T. Kuda, H. Goto, M. Yokoyama, and T. Fujii, "Effects of dietary concentration of laminaran and depolymerised alginate on rat cecal microflora and plasma lipids," Fisheries Science, vol. 64, no. 4, pp. 589-593, 1998. 
[65] T. Kuda, T. Yano, N. Matsuda, and M. Nishizawa, "Inhibitory effects of laminaran and low molecular alginate against the putrefactive compounds produced by intestinal microflora in vitro and in rats," Food Chemistry, vol. 91, no. 4, pp. 745-749, 2005.

[66] I. Pajic-Lijakovic, S. Levic, M. Hadnađev et al., "Structural changes of Ca-alginate beads caused by immobilized yeast cell growth," Biochemical Engineering Journal, vol. 103, pp. 32-38, 2015.

[67] F. E. Vasile, A. M. Romero, M. A. Judis, and M. F. Mazzobre, "Prosopis alba exudate gum as excipient for improving fish oil stability in alginate - chitosan beads," Food Chemistry, vol. 190, pp. 1093-1101, 2016.

[68] F. Mancini, L. Montanari, D. Peressini, and P. Fantozzi, "Influence of alginate concentration and molecular weight on functional properties of mayonnaise," LWT-Food Science and Technology, vol. 35, no. 6, pp. 517-525, 2002.

[69] O. Aizpurua-Olaizola, P. Navarro, A. Vallejo, M. Olivares, N. Etxebarria, and A. Usobiaga, "Microencapsulation and storage stability of polyphenols from Vitis vinifera grape wastes," Food Chemistry, vol. 190, pp. 614-621, 2016.

[70] W. Cheng, C.-H. Liu, C.-M. Kuo, and J.-C. Chen, "Dietary administration of sodium alginate enhances the immune ability of white shrimp Litopenaeus vannamei and its resistance against Vibrio alginolyticus," Fish and Shellfish Immunology, vol. 18, no. 1, pp. 1-12, 2005.

[71] M. D. Wilcox, I. A. Brownlee, J. C. Richardson, P. W. Dettmar, and J. P. Pearson, "The modulation of pancreatic lipase activity by alginates," Food Chemistry, vol. 146, pp. 479-484, 2014.

[72] B. An, H. Lee, S. Lee, S. Lee, and J. Choi, "Determining the selectivity of divalent metal cations for the carboxyl group of alginate hydrogel beads during competitive sorption," Journal of Hazardous Materials, vol. 298, pp. 11-18, 2015.

[73] W. Cheng, R.-T. Tsai, and C.-C. Chang, "Dietary sodium alginate administration enhances $\mathrm{Mx}$ gene expression of the tiger grouper, Epinephelus fuscoguttatus receiving poly I:C," Aquaculture, vol. 324-325, pp. 201-208, 2012.

[74] S.-T. Chiu, R.-T. Tsai, J.-P. Hsu, C.-H. Liu, and W. Cheng, "Dietary sodium alginate administration to enhance the nonspecific immune responses, and disease resistance of the juvenile grouper Epinephelus fuscoguttatus," Aquaculture, vol. 277, no. 1-2, pp. 66-72, 2008.

[75] C.-H. Liu, S.-P. Yeh, C.-M. Kuo, W. Cheng, and C.-H. Chou, "The effect of sodium alginate on the immune response of tiger shrimp via dietary administration: activity and gene transcription," Fish and Shellfish Immunology, vol. 21, no. 4, pp. 442$452,2006$.

[76] K. Fujiki and T. Yano, "Effects of sodium alginate on the nonspecific defence system of the common carp (Cyprinus carpio L.)," Fish and Shellfish Immunology, vol. 7, no. 6, pp. 417-427, 1997.

[77] H. Tomida, T. Yasufuku, T. Fujii, Y. Kondo, T. Kai, and M. Anraku, "Polysaccharides as potential antioxidative compounds for extended-release matrix tablets," Carbohydrate Research, vol. 345, no. 1, pp. 82-86, 2010.

[78] L. L. Oglesby, S. Jain, and D. E. Ohman, "Membrane topology and roles of Pseudomonas aeruginosa Alg8 and Alg44 in alginate polymerization," Microbiology, vol. 154, no. 6, pp. 1605-1615, 2008.

[79] I. M. Saxena, R. M. Jr. Brown, M. Fevre, R. A. Geremia, and B. Henrissat, "Multidomain architecture of $\beta$-glycosil tranferases: implications for mechanism of action," Journal of Bacteriology, vol. 177, no. 6, pp. 1419-1419, 1995.

[80] U. Remminghorst and B. H. A. Rehm, "In vitro alginate polymerization and the functional role of Alg8 in alginate production by Pseudomonas aeruginosa," Applied and Environmental Microbiology, vol. 72, no. 1, pp. 298-305, 2006.

[81] M. Merighi, V. T. Lee, M. Hyodo, Y. Hayakawa, and S. Lory, “The second messenger bis- $\left(3^{\prime}-5^{\prime}\right)$-cyclic-GMP and its PilZ domaincontaining receptor Alg 44 are required for alginate biosynthesis in Pseudomonas aeruginosa," Molecular Microbiology, vol. 65, no. 4, pp. 876-895, 2007.

[82] S. Alexeeva, K. J. Hellingwerf, and M. J. Teixeira de Mattos, "Quantitative assessment of oxygen availability: perceived aerobiosis and its effect on flux distribution in the respiratory chain of Escherichia coli," Journal of Bacteriology, vol. 184, no. 5, pp. 1402-1406, 2002.

[83] J. Oelze, "Respiratory protection of nitrogenase in Azotobacter species: Is a widely held hypothesis unequivocally supported by experimental evidence?" FEMS Microbiology Reviews, vol. 24, no. 4, pp. 321-333, 2000.

[84] M. A. Trujillo-Roldán, S. Moreno, D. Segura, E. Galindo, and G. Espín, "Alginate production by an Azotobacter vinelandii mutant unable to produce alginate lyase," Applied Microbiology and Biotechnology, vol. 60, no. 6, pp. 733-737, 2003.

[85] M. A. Trujillo-Roldán, S. Moreno, G. Espín, and E. Galindo, "The roles of oxygen and alginate-lyase in determining the molecular weight of alginate produced by Azotobacter vinelandii," Applied Microbiology and Biotechnology, vol. 63, no. 6, pp. 742-747, 2004.

[86] A. Díaz-Barrera, C. Peña, and E. Galindo, “The oxygen transfer rate influences the molecular mass of the alginate produced by Azotobacter vinelandii," Applied Microbiology and Biotechnology, vol. 76, no. 4, pp. 903-910, 2007.

[87] A. Díaz-Barrera, P. Silva, R. Ávalos, and F. Acevedo, "Alginate molecular mass produced by Azotobacter vinelandii in response to changes of the $\mathrm{O}_{2}$ transfer rate in chemostat cultures," Biotechnology Letters, vol. 31, no. 6, pp. 825-829, 2009.

[88] E. Lozano, E. Galindo, and C. F. Peña, "Oxygen transfer rate during the production of alginate by Azotobacter vinelandii under oxygen-limited and non oxygen-limited conditions," Microbial Cell Factories, vol. 10, article 13, 2011.

[89] C. Peña, M. A. Trujillo-Roldán, and E. Galindo, "Influence of dissolved oxygen tension and agitation speed on alginate production and its molecular weight in cultures of Azotobacter vinelandii," Enzyme and Microbial Technology, vol. 27, no. 6, pp. 390-398, 2000.

[90] J. Green and M. S. Paget, "Bacterial redox sensors," Nature Reviews Microbiology, vol. 2, no. 12, pp. 954-966, 2004.

[91] G. Wu, A. J. G. Moir, G. Sawers, S. Hill, and R. K. Poole, "Biosynthesis of poly- $\beta$-hydroxybutyrate (PHB) is controlled by CydR (Fnr) in the obligate aerobe Azotobacter vinelandii," FEMS Microbiology Letters, vol. 194, no. 2, pp. 215-220, 2001.

[92] A. Díaz-Barrera, R. Andler, I. Martínez, and C. Peña, "Poly-3hydroxybutyrate production by Azotobacter vinelandii strains in batch cultures at different oxygen transfer rates," Journal of Chemical Technology \& Biotechnology, 2015.

[93] J. M. Martínez-Salazar, S. Moreno, R. Nájera et al., "Characterization of the genes coding for the putative sigma factor $A \lg U$ and its regulators $\mathrm{MucA}, \mathrm{MucB}, \mathrm{MucC}$, and $\mathrm{MucD}$ in Azotobacter vinelandii and evaluation of their roles in alginate biosynthesis," Journal of Bacteriology, vol. 178, no. 7, pp. 1800$1808,1996$. 
[94] R. León and G. Espín, “ $f l h D C$, but not fleQ, regulates flagella biogenesis in Azotobacter vinelandii, and is under $\mathrm{AlgU}$ and CydR negative control," Microbiology, vol. 154, no. 6, pp. 17191728, 2008.

[95] C. Núñez, A. V. Bogachev, G. Guzmán, I. Tello, J. Guzmán, and G. Espín, "The $\mathrm{Na}^{+}$-translocating NADH: ubiquinone oxidoreductase of Azotobacter vinelandii negatively regulates alginate synthesis," Microbiology, vol. 155, no. 1, pp. 249-256, 2009.

[96] Y. V. Bertsova, A. V. Bogachev, and V. P. Skulachev, "Noncoupled NADH: ubiquinone oxidoreductase of Azotobacter vinelandii is required for diazotrophic growth at high oxygen concentrations," Journal of Bacteriology, vol. 183, no. 23, pp. 6869-6874, 2001.

[97] M. Bekker, S. Alexeeva, W. Laan, G. Sawers, J. T. De Mattos, and K. Hellingwerf, "The ArcBA two-component system of Escherichia coli is regulated by the redox state of both the ubiquinone and the menaquinone pool," Journal of Bacteriology, vol. 192, no. 3, pp. 746-754, 2010.

[98] D. Georgellis, O. Kwon, and E. C. C. Lin, "Quinones as the redox signal for the Arc two-component system of bacteria," Science, vol. 292, no. 5525, pp. 2314-2316, 2001.

[99] R. Malpica, G. R. Peña Sandoval, C. Rodríguez, B. Franco, and D. Georgellis, "Signaling by the Arc two-component system provides a link between the redox state of the quinone pool and gene expression," Antioxidants and Redox Signaling, vol. 8, no. 5-6, pp. 781-795, 2006. 

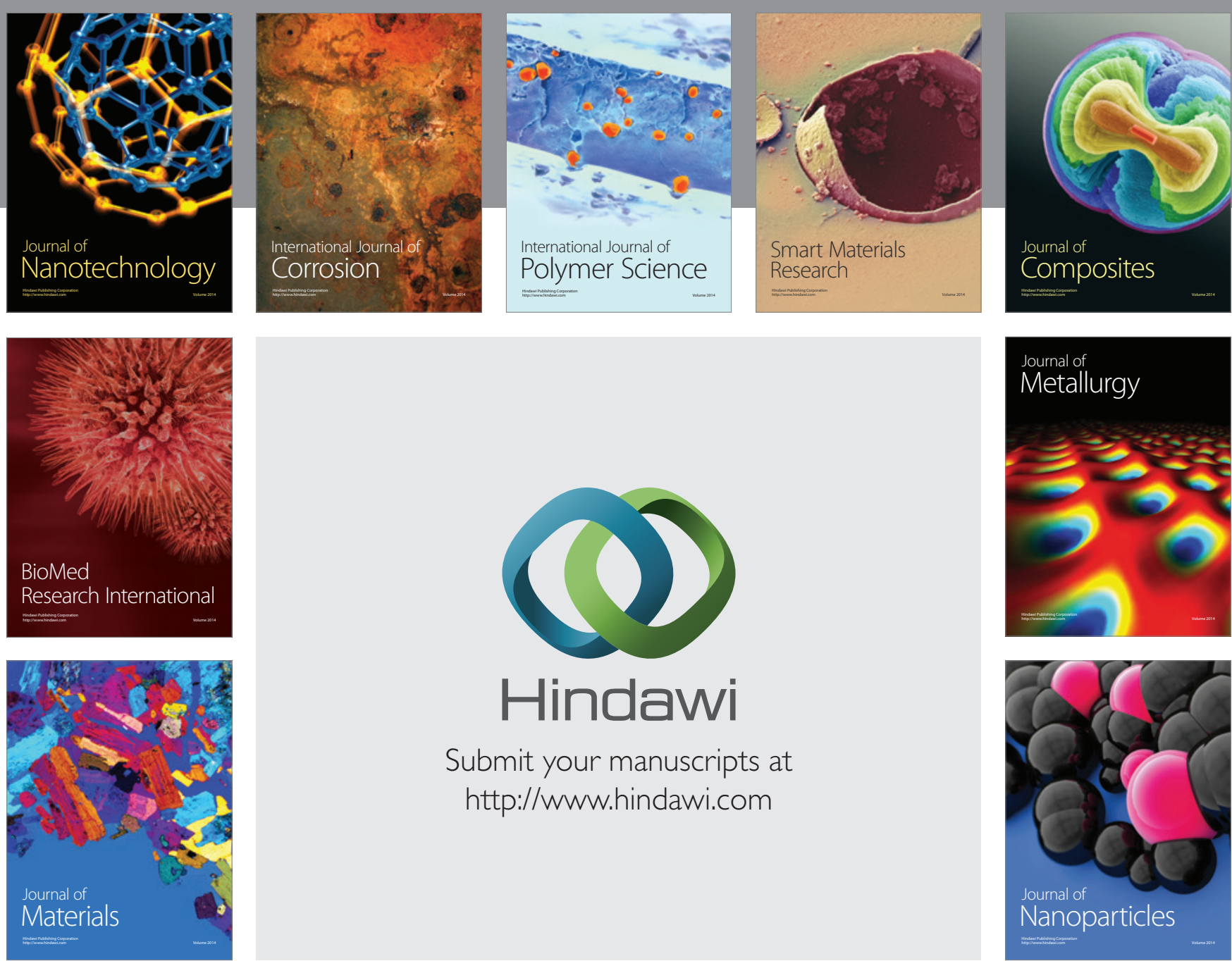

\section{Hindawi}

Submit your manuscripts at

http://www.hindawi.com

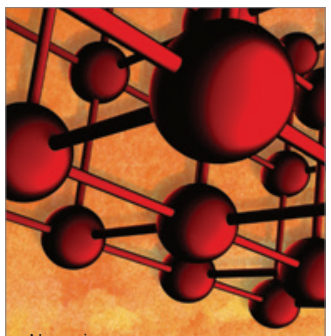

Materials Science and Engineering
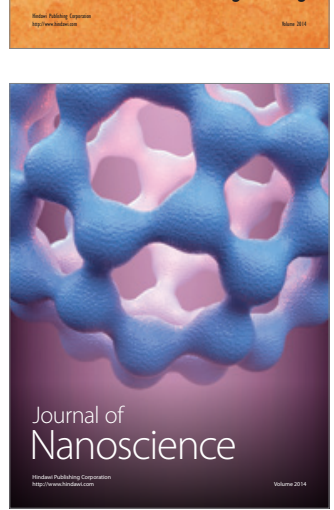
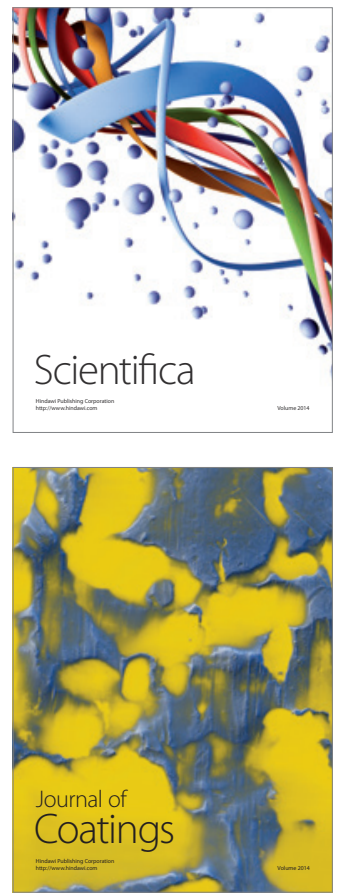
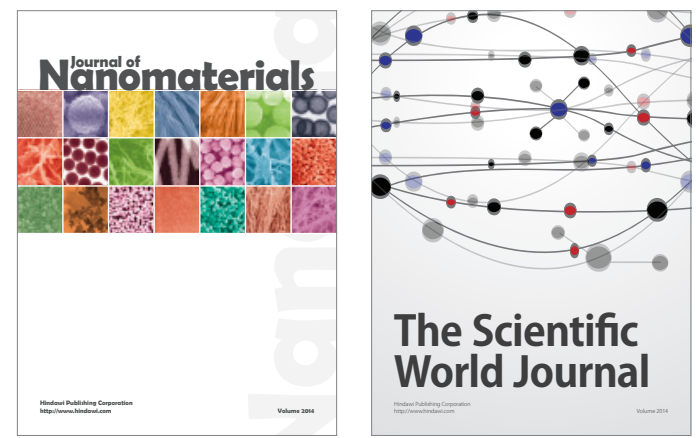

The Scientific World Journal
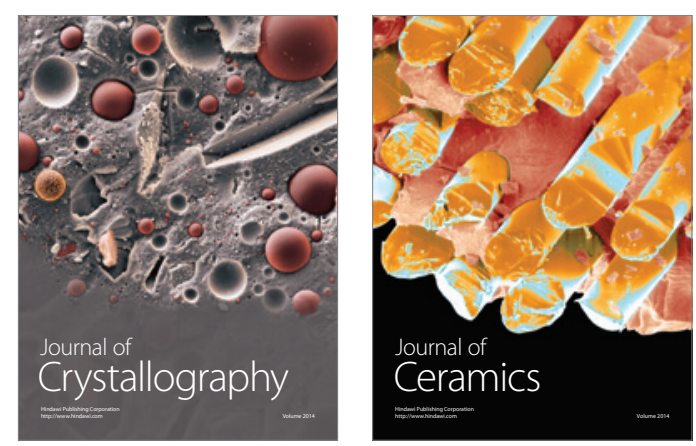
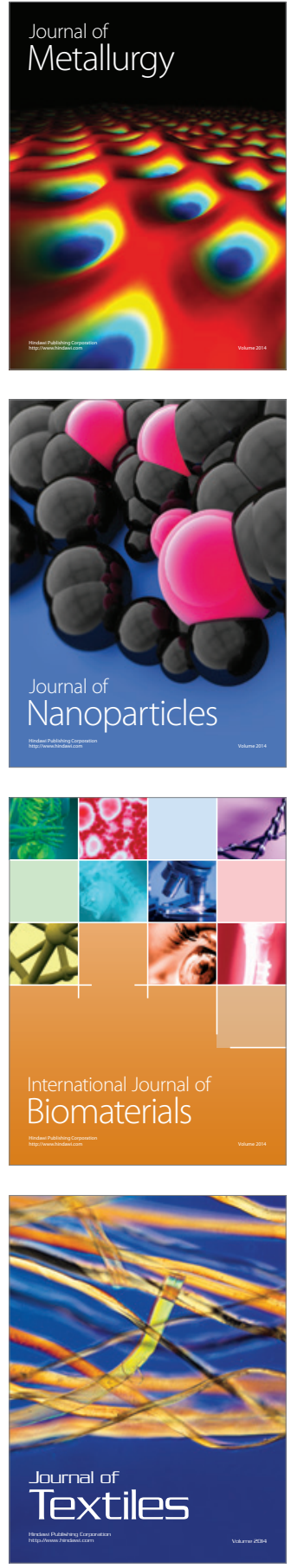